\title{
Lipids, glucose parameters and reversible immunosuppression induced by Methylprednisolone on healthy rabbits.
}

\author{
Yapi Houphouet Félix ${ }^{* 1}$; Yapo Adou${ }^{1}$; Bidie Alain Philippe ${ }^{1}$,Ahiboh Hugues ${ }^{2}$; Yayo \\ Eric $^{2}$; Hauhouot-Attounbre Marie-Laure ${ }^{2}$, Nguessan-Edjeme Angèle ${ }^{2}$, , Djaman \\ Allico Joseph ${ }^{1}$,Monnet Dagui ${ }^{2}$ \\ ${ }^{1}$ Laboratoire de Pharmacodynamie-Biochimique, UFR Biosciences, Université de Cocody- \\ Abidjan (Côte d'Ivoire), 22 BP 1679 Abidjan 22 \\ ${ }^{2}$ Laboratoire Biochimie et biologie moléculaire, UFR Sciences Pharmaceutiques et \\ Biologiques, Université de Cocody-Abidjan (Côte d'Ivoire), BP V 34 Abidjan
}

\begin{abstract}
:
Single doses of Methylprednisolone hemisuccinate were tested in healthy rabbits. This study was conducted to determine the dose or doses that induce significant immunosuppression without significantly altering the serum levels of lipids and glucose within a relatively long period. Thus, four concentrations of methylprednisolone $(2.5,5,10$ and $15 \mathrm{mg} / \mathrm{kg}$ body weight) were tested on four groups of six rabbits and a control group $(0.9 \% \mathrm{NaCl})$. The results of this study showed that only concentrations of 10 and $15 \mathrm{mg} / \mathrm{kg}$ body weight induced a significant immunosuppression within seven days $(P<0.05)$. Furthermore, with a dose of $15 \mathrm{mg} / \mathrm{kg}$ body weight serum concentrations of triglycerides and glucose were increased significantly $(P<0.05)$ while other doses had no effect on other biological parameters $(P>0.05)$. The results of this study suggest that the dose of $10 \mathrm{mg} / \mathrm{kg}$ body weight could be given as a dose inducing reversible immunosuppression without significantly altering the lipid and glucose parameters. The increase of lipids and glucose may cause diseases such as dyslipidemia and diabetes which could give rise to an irreversible immunosuppression.
\end{abstract}

Keywords: Immunodepression, Methylprednisolone, Rabbit, lipids, glucose, Côte d'Ivoire

\section{INTRODUCTION}

Inflammation and immunosuppression were observed in the occurrence of metabolic diseases such as diabetes mellitus (Tanaka, 2008; Rubinstein et al., 2008) and dyslipidemia (Kakei et al., 2009; Zhao, 2009). Plants that have anti-inflammatory and immunogenic are searched for in the treatment of inflammatory diseases and immunodeficiency in humans (Gutpa et al., 1971; Mankele et al., 2006). Several studies have highlighted the antiinflammatory properties of certain plants (Holanda et al., 2008). In these studies, inflammation was induced in experimental animals to test for plants that may possess anti-inflammatory properties. But study on the evaluation of immunogenic activity of plants such as Mankele et al. (2006), Kra et al. (2007), have not undergone prior immunosuppression in animals. Whereas it is logical and normal that animal that is used to assess the immunogenic properties of plants should be put first in a state of reversible immunocompromised.This will allow for effective verification in vivo of immunogenic properties of plants if we noticed any stimulation of immunological markers in animals. The aim of present study was therefore to determine the doses or dose of Methylprednisolone (MP) hemisuccinate which induce significant immunosuppression within a relatively long time without significant changes in lipid and glucose in rabbits.

\section{MATERIALS AND METHODS}

\section{MATERIALS}

Methylprednisolone

Immunosuppressive ): The immunosuppressant used was methylprednisolone (MP) hemisuccinate (Solu-Medrol @) from the Laboratory Pharamacia $(8$ (France). This is an anti-inflammatory steroid (AIS) used in the treatment of inflammatory diseases and transplant rejection Richter et al., 1983; Heideman and Bengstson, 1985)

Laboratory animal: In this study, thirty (30) rabbits of the species Orictolagus cuniculus (Leporideae), aged 3 months and whose average weight was $1.5 \pm 0.3$ $\mathrm{kg}$, were used. These animals were acclimated in the animal unit of teaching and research (Faculty) of Biosciences (University of Cocody) at room 
temperature of $25^{\circ} \mathrm{C}$. They were brought from a farm located in Bingerville (Southeast Abidjan). They had access to tap water and poultry feeds (pellets from Ivograins $(\AA)$. Animal suffering has been minimized by applying the terms of the Guide for Care and Use of Laboratory Animals (National Academy of Sciences, 1996). The animals were divided into five groups of six rabbits.

\section{METHODS}

Administration of methylprednisolone (MP) hemisuccinate (Solu-Medrol): The administration of methylprednisolone (MP) hemisuccinate in all rabbits were made intraperitoneally in a single dose. The control group $(\mathrm{C})$ received a single dose injection of $0.9 \% \mathrm{NaCl}$ intraperitoneally. Other rabbits received different doses of MP according to body weight (BW). Thus, doses of $2.5,5,10$ and $15 \mathrm{mg} / \mathrm{kg}$ of $B W$ were administered has allowed us to constitute different lots respectively Lot I Lot II Lot III Lot IV.

\section{Method of sampling and assay of biological parameters}

-blood Collection: The blood was collected in the morning from the marginal vein in the ear of rabbit on the first day (D0) before the administration of $\mathrm{NaCl}$ and different doses of MP hemisuccinate. After the administration of $\mathrm{NaCl}$ and different doses of $\mathrm{MP}$ hemisuccinate, samples were taken in succession on the third day (D3), the sixth day (D6), the ninth day (J9), the twelfth day (J12) and the fifteenth day (D15).

Determination of markers of cellular immunity: Whole blood collected in EDTA tubes was used for assay of markers of cellular immunity: White blood cell (WBC), lymphocytes and neutrophils. These cellular immunological markers were assayed by a semi-automatic (XT-20001-1-System $\AA$, Germany).

-Determination of lipids and glucose: The serum obtained after centrifugation (3500 rpm) for five (5) minutes of whole blood, made possible the assay of the lipid parameters (total cholesterol (TC), HDLcholesterol, triglycerides) and glucose by the enzyme peroxidase method (Trinder, 1969; Allain et al.,1974; Grove, 1979) . The principles for determination of biochemical parameters are as follows:

* Cholesterol is oxidized by cholesterol oxidase to cholesten 4 one 3 and hydrogen peroxide. hydrogen peroxide reacts in the presence of peroxidase with 4chloro-phenol and 4-amino-antipyrine to form a pink quinoneimine. The absorbance of colored complex, proportional to the concentration of glucose was measured at 500nm. * The HDL-cholesterol obtained after precipitation of serum by mixing phosphotungstic acid and magnesium chloride. Determining the concentration of HDL-cholesterol follows the same principle as that of total cholesterol. * Glucose is oxidized by glucose oxidase to gluconic acid and hydrogen peroxide. Hydrogen peroxide reacts in the presence of peroxidase with 4chloro-phenol and 4-amino-antipyrine to form a red quinoneimine. The absorbance of colored complex, proportional to the concentration of glucose was measured at $500 \mathrm{~nm}$. * The triglycerides were hydrolyzed into glycerol and free fatty acids. Glycerol by the action of glycerol kinase and glycerol 3 phosphate oxidase gives hydrogen peroxide. Hydrogen peroxide reacts in the presence of peroxidase with 4-chloro-phenol and 4-aminoantipyrine to form a pink quinoneimine. The absorbance of colored complex, proportional to the concentration of triglycerides was measured at $500 \mathrm{~nm}$. All biochemical parameters were measured by Kenza Max Biochemistry, Biolabo ${ }^{\circledR}$, France.

Statistical Analysis: The analysis of variance (ANOVA) following Dunnett's test (nonparametric test suitable for small numbers) was used to compare mean values of biological parameters of different constituted lots. The difference is considered significant between two means if $\mathrm{P}<0.05$.

\section{RESULTS}

Immunity markers: The results of this study showed that the increase in average count of white blood cells in D3 was significant compare to DO only in the control $(P<0.05)$ (Figure 1). At this same period, it was observed compase in average count of neutrophils was observed in day 3 with a dose of 2.5 $\mathrm{mg} / \mathrm{kg}$ BW of MP $(3.10 \pm 0.49$. 103/ $/ \mathrm{l})$ compared

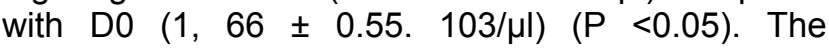
significant decrease in white blood cells observed with a dose of $2.5 \mathrm{mg} / \mathrm{kg} \mathrm{BW}$ of MP on days 6 and 9 is also noted with a dose of $15 \mathrm{mg} / \mathrm{kg} \mathrm{BW}$ of MP on days 9 and $12(P<0.05)$ (Figure 1$)$. It is noted that the only significant decrease in lymphocytes induced by doses of 10 and $15 \mathrm{mg} / \mathrm{kg}$ BW of MP lasted seven $(7)$ days $(P<0.05)$ (Figure 1$)$.

Biochemical parameters: Figure 3 shows that the doses of MP did not significantly alter the average total cholesterol compared to control ( $P>0.05$ ). However, this average count falls within normal values of total cholesterol in rabbits. With regard to triglycerides, the doses of 2.5, 5 and $10 \mathrm{mg} / \mathrm{kg} \mathrm{BW}$ of MP did not significantly alter the serum 
Agric. Biol. J. N. Am., 2011, 2(1): 182-187

concentration compare to control ( $P>0.05)$ (Figure4). In contrast, only the single doses of $15 \mathrm{mg}$ / kg BW has increased significantly triglycerides ( $P$ $<0.05$ )from D3 to D15. One notices from D9 to D15 decreased amplitude levels of triglycerides compared to $\mathrm{J} 3$ and $\mathrm{J} 6$.

Figure 5 shows that all doses of MP (2.5 to $15 \mathrm{mg} /$ $\mathrm{kg}$ BW) had no effect on serum concentration levels of HDL-cholesterol compared to control ( $P>0.05$ ). However, this concentration remains within normal range $\mathrm{HDL}-\mathrm{C}$ in rabbits. However, the dose of $15 \mathrm{mg}$ / $\mathrm{kg}$ BW of MP induced a significant increase in serum glucose $(P<0.05)$ following a parabolic curve to about $2 \mathrm{~g} / \mathrm{I}$ in contrast to other experimental doses that have no effect ( $P>0.05$ ) (Figure6). Although the doses of MP have induced immunosuppression, only the dose of $15 \mathrm{mg} / \mathrm{kg}$ of BW induced a significant change in serum glucose and triglycerides.

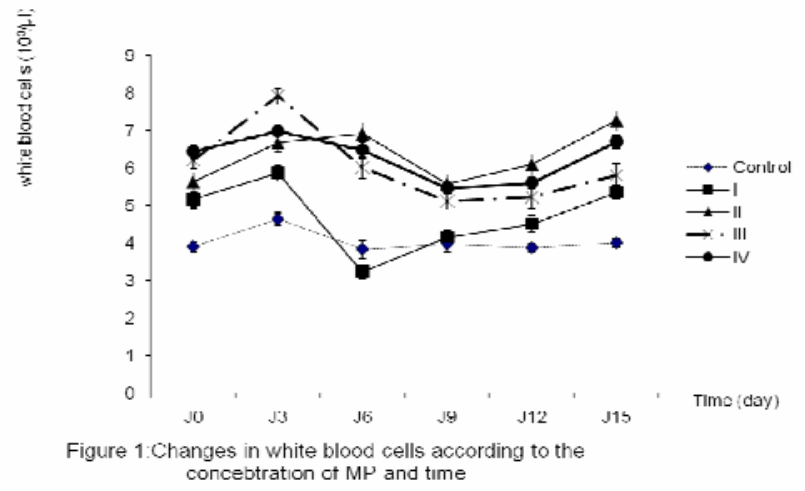

I=Lot of rabbit that have received $2.5 \mathrm{mg} / \mathrm{kg}$ of MP; II=Lot of rabbit that have received $5 \mathrm{mg} / \mathrm{kg}$ of MP; III=Lot of rabbit that have received $10 \mathrm{mg} / \mathrm{kg}$ of MP;IV=Lot of rabbit that have received $15 \mathrm{mg} / \mathrm{kg}$ of MP.

$a, b$,and e represent each comparison made between average value of the day compare to that of $D O$ in each Lot.

a=average $\mathrm{WBC}$ of the control at D3 significantly high compare to D0

$\mathrm{b}=$ average WBC with $2.5 \mathrm{mg} / \mathrm{kg}$ of MP (I) significantly low at D6 and D9 compare to DO

$\mathrm{e}=$ average WBC with $15 \mathrm{mg} / \mathrm{kg}$ of MP(IV)significantly low at D9 and D12 compared to D0

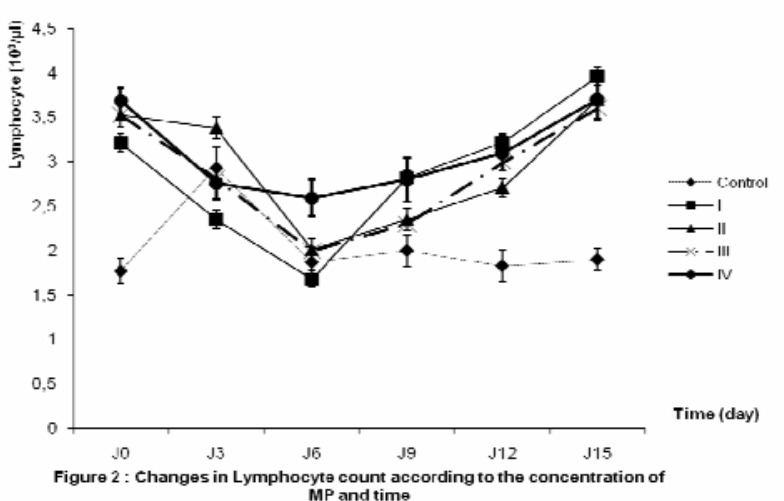

I=Lot of rabbit that have received $2.5 \mathrm{mg} / \mathrm{kg}$ of $\mathrm{MP} ; \|=\mathrm{L}$ ot of rabbit that have received $5 \mathrm{mg} / \mathrm{kg}$ of MP; III=Lot of rabbit that have received $10 \mathrm{mg} / \mathrm{kg}$ of $\mathrm{MP} ; \mathrm{IV}=\mathrm{Lot}$ of rabbit that have received $15 \mathrm{mg} / \mathrm{kg}$ of MP.

a,b,c,d and e represent each comparison made between average value of the day compare to that of DO in each Lot.

a=average count of lymphocyte of control significantly high compare to DO

$b=$ average count of lymphocyte with $2.5 \mathrm{mg} / \mathrm{kg}$ of $M P(I)$ significantly low in D6 compared to DO

c=average count of lymphocyte with $5 \mathrm{mg} / \mathrm{kg}$ of $M P(I I)$ significantly Inin in D6 compared to DO

$d=$ average count e ymphocyte with $10 \mathrm{mg} / \mathrm{kg}$ of $M P$ (III)significantly low in D3,D6 and D9 compared to DO e=average lymphocyte count with $15 \mathrm{mg} / \mathrm{kg}$ of $\mathrm{MP}$ (III)significantly low in D3,D6 and D9 compared to DO

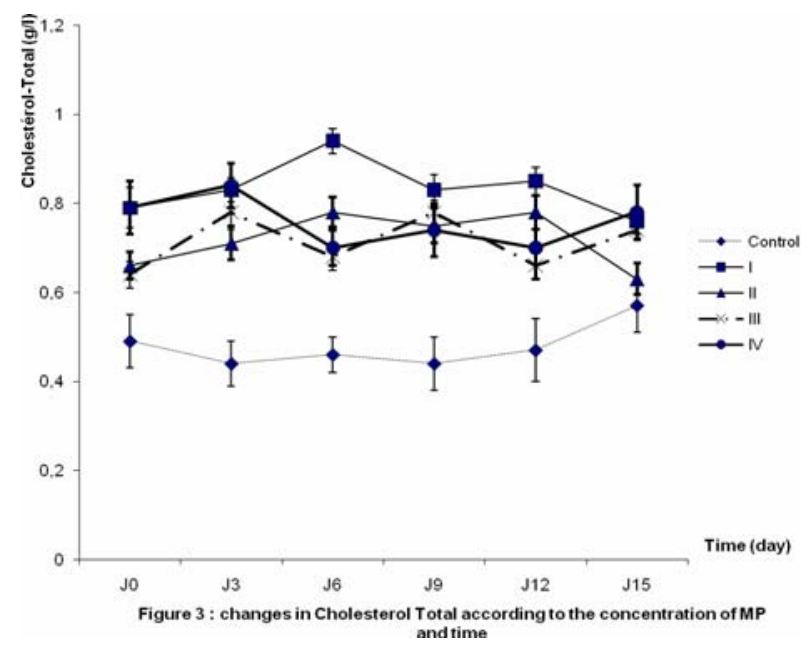




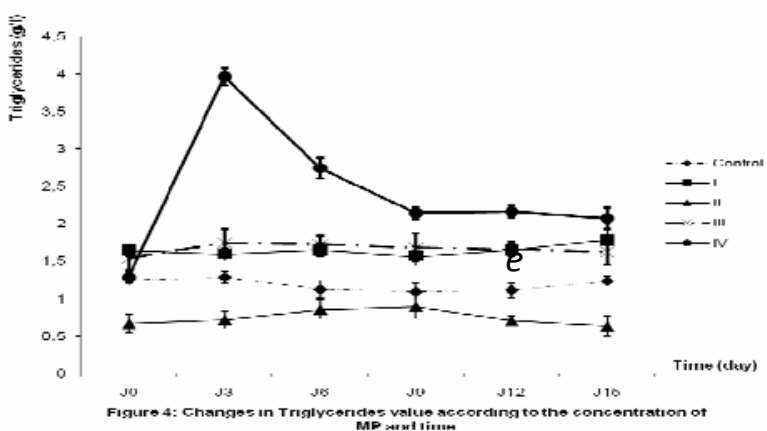

I=Lot of rabbit that have received $2.5 \mathrm{mg} / \mathrm{kg}$ of MP;II=Lot of rabbit that have received $5 \mathrm{mg} / \mathrm{kg}$ of MP; III=Lot of rabbit that have received $10 \mathrm{mg} / \mathrm{kg}$ of $\mathrm{MP} ; \mathrm{IV}=\mathrm{Lot}$ of rabbit that have received $15 \mathrm{mg} / \mathrm{kg}$ of MP.

e represent the comparison made between the average value of the day compare to that of DO of Lot IV

e=average Triglyceride value with $15 \mathrm{mg} / \mathrm{kg}$ of MP (III)significantly high in D3,D6,D9,D12 and D15 compared to DO

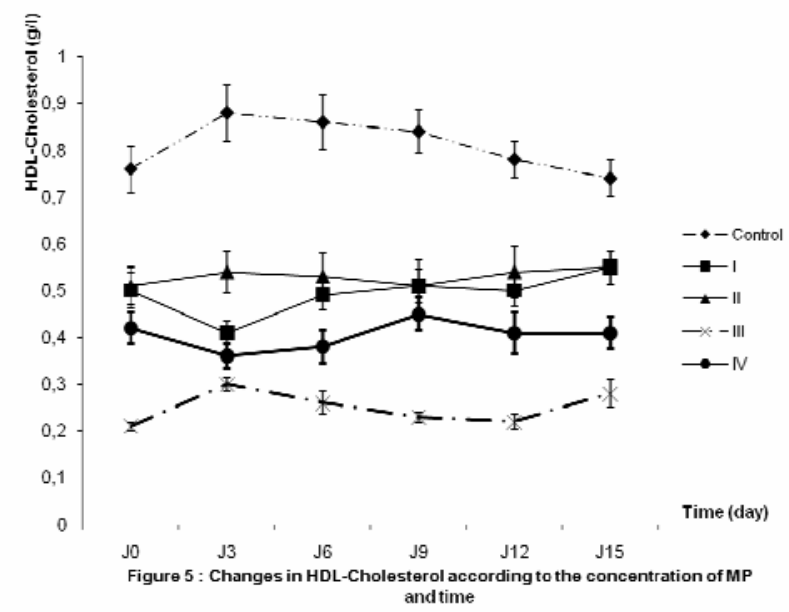

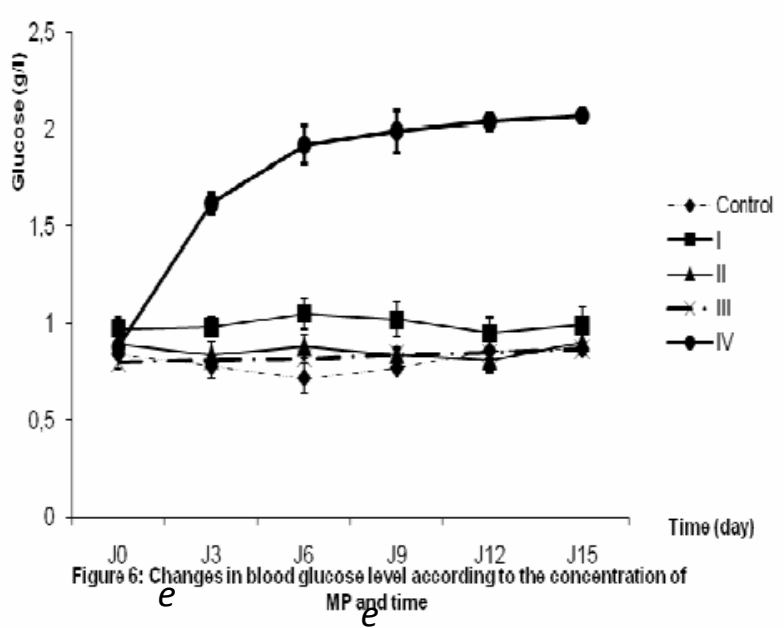

e represent the comparison made between the average value of the day compare to that of DO of Lot IV

e=average blood sugar with $15 \mathrm{mg} / \mathrm{kg}$ of MP (IV) significantly high in D3, D6,D9,D12 and D15

\section{DISCUSSION}

In this study, the concentration of MP used is between 2.5 and $15 \mathrm{mg} / \mathrm{kg}$ of body weight (BW). This concentration range is proposed to better identify the ideal concentration of MP and the time needed to induce reversible immunosuppression in rabbits.

The results obtained during this study showed that 10 and $15 \mathrm{mg} / \mathrm{kg}$ BW of MP induced reversible immunosuppression for seven (7) days (D3 to D9).The increase in average count of lymphocytes and WBC on day 3 after injection of $\mathrm{NaCl}$ could be attributed to a local inflammatory process caused by the injection needle. Indeed, according to the work of Caldwell et al. (2007); Ramadori et al. (2008) during inflammation, lymphocytes and neutrophils are mobilized. They thus reduce inflammation through the secretion of cytokines, including interleukin IL-17 (Caldwell et al., 2005). The increase in neutrophils and decreased in lymphocytes in the Lot I could be explained by the fact that the concentration of $2.5 \mathrm{mg}$ / $\mathrm{kg}$ of MP does not allow the two therapeutic properties known of MP (anti-inflammatory and immunosuppressive ) to take place as $\mathrm{P}$. Richter et al. (1983). With this concentration, it is immunosuppressive property that overrides antiinflammatory effect.Immunosuppressive and antiinflammatory properties of MP hemisuccinate at 
doses of 5,10 and $15 \mathrm{mg} / \mathrm{kg} \mathrm{BW}$ of MP suggests that the minimum dose capable of providing both therapeutic properties known of MP is $5 \mathrm{mg} / \mathrm{kg} \mathrm{BW}$. Furthermore, white blood cells that reduce from D9 to D12 suggest that the dose of $15 \mathrm{mg} / \mathrm{kg}$ MP could weaken the body organism more than $10 \mathrm{mg} / \mathrm{kg}$ of BW.

The steady increase in glucose and triglycerides increase after D3 with $15 \mathrm{mg} / \mathrm{kg} \mathrm{MP}$, seem to suggest that this dose of $15 \mathrm{mg} / \mathrm{kg}$ MP may induce dyslipidemia and diabetes in rabbits. Indeed, the normal value of triglycerides is between 1.24 and $1.56 \mathrm{~g} / \mathrm{I}$ (Boucher and Mouaille, 1996) and that of the blood sugar is between 0.77 and $1.55 \mathrm{~g} / \mathrm{I}$ (Sakande et al., 2003). According to Dessein et al. (2005) and Jin and Jusko (2009), the dose of $15 \mathrm{mg} /$ $\mathrm{kg}$ of MP stimulate gluconeogenesis and lipogenesis than other doses of MP. All these observations suggest that the dose of 10 $\mathrm{mg} / \mathrm{kg}$ of MP would be more appropriate in the induction of reversible immunosuppression for an experimental study without causing disturbances of immunological factors that can make this irreversible induction.

\section{CONCLUSION}

The experimental study, carried out allowed us to deduct that concentrations of 10 and $15 \mathrm{mg} / \mathrm{kg}$ of BW are required for induction of a reversible immunosuppression for seven (7) days. However, the dose that does not alter lipid and glucose parameters and induces a good reversible immunosuppression, is the concentration of $10 \mathrm{mg} / \mathrm{kg} 15 \mathrm{mg} / \mathrm{kg} \mathrm{BW}$ unlike $15 \mathrm{mg} / \mathrm{kg}$ of BW which could be likely to induce dyslipidemia and diabetes mellitus, known in the irreversible immunosuppression.

\section{REFERENCES}

Allain C C, Poon L S, Chan C S. G, Richmond W et Fu P C (1974). Enzymatic determination of Total Serum Cholesterol. Clin. Chem. 20: 470-475.

Boucher S et Mouaille L (1996). Maladies des lapins. Manuel pratique. Edition France Agricole, 225p.

Caldwell CC, Tschoep J, Lentsch A B (2007). Lymphocytes function during hepatic ischemia/reperfusion injury. J. Leukoc. Biol. 457464.

Caldwell CC, Okaya T, Martigoni A, Husted T, Schuster $R$ et Lentsch A B (2005) .Divergent functions of CD4+ Tlymphocytes in acute liver inflammation and injury after ischemia-reperfusion. Am. J. Physiol. Gastrointest. Liver Physiol.289 :G969-G976.
Dessein PH, Joffe B I, Stanwix AE, Christian BF et Veller M (2005). Glucocorticoids and insulin sensitivity in rheumatoid arthritis. J. Rheumato.31 (5): 867-74.

Grove T H (1979). Effect of reagent $\mathrm{Ph}$ on determination of HDL-Cholestérol by precipitation with Sodium Phosphotungstate-magnesium. Clin Chem.25: 560.

Gutpta M B, Bhalla TN, Gutta GP, Mitra CR et Bharargawa KP (1971). Anti-inflammatory activity of Taxifolin. Japan. J. Pharmacol. 21 :377-382.

Heideman $M$ et Bengtson A (1985). Immunological interference of high concentration corticoids. Acta. Chir. Scand. Suppl. 526:48-55.

Holanda P S A, Pinto LMS, Cunha GMA, Chaves MH, Santos F A et Rao. VS (2008). Anti-inflammatory effect of $\alpha, \beta$-Amyrin , a pentacycyclic triterpene from Protium heptaphyllum in rat model of acute periodontitis. Inflammopharmacology.16:48-52.

Jin J Y et Jusko WJ (2009). Pharmacodynamics of glucose regulation by methylprednisolone. I. Adrenalecttomized rats. Biopharm. Drug. Dispo. 30 (1) :21-34.

Kakaei F, Nikeghbalian S, Kazemi K, Salahi H, Bahador A, Dehghani SM, Dehghani M, Nejatollahi SM, Shamsaeefar A, Khosravi MB et Malek-Hosseini SA (2009). Liver transplantation for homozygous familial hypercholesterolemia: two case reports. Transplant Proc.41 (7): 2939-41.

Kra A K M, Zirihi G N et Guede-Guina F (2007). Kouadio., Activité immunostimulante (in vivo chez le lapin) de NR1A, une fraction glycoprotéique isolée à partir de Aerva lanata ( $L$ ) juss. Ex Schlt (Amaranthaceae), une plante médecinale de la pharmacopée ivoirienne. Rev. Med. Pharm. Afr. 20 :19-24.

Mankele R, Ouamba J M, Abena AA et Yala F (2006). Étude des effets de Morinda morindoides (Back) sur le système immunitaire de l'homme. Phytothérapie.4: 68-73.

National Academy Sciences., Guide for care and use of laboratory animals. Institute of Laboratory Animals Resources commission on life sciences (National research council), National Academy Press, Washington, D.C, (1996)134p.

Ramadori G, Moriconi F, Malik I et Duda J (2008). Physiology and pathophysiology of liver inflammation damage and repair. $J$.Physiol .Pharmacol.59 (1) :107-117 
Agric. Biol. J. N. Am., 2011, 2(1): 182-187

Richter M B, Woo P, Panayi G S, Trull A, Unger A et Shepherd $P$ (1983) The effects of intravenous pulse methylprdnisolone on immunological and inflammatory processes in ankylosing spondylitis. Clin. Exp. Immunol.53: 51-59.

Rubinstein R, Genaro AM, Motta A, Cremaschi G et Wald MR (2008). Impaired immune responses in streptozotocin-induced type I diabetes in mice. Involvement of high glucose. Clin Exp Immunol. 154 (2): 235-46.

Sakande J, Ahiboh H, Edjelme A et Yapo AE (2003). Etude de la tolerance biologique d'une plante a activité antiplasmodiale Momordica Charantia L (Cucurbitaceae). Mali. med.18 (1-2) :1-4.

Tanaka Y (2008). Immunosuppressive mechanisms in diabetes mellitus. Nippon Rinsho.66 (12): 2233-7.

Trinder P (1969). Determination of blood glucose using an oxidase peroxidase system with a noncarcinogenic chromogen. Ann Clin Biochem. 6:2729.

Zhao Q (2009). Inflammation, autoimmunity, and atherosclerosis. Discov Med. 8 (40):7-12. 